\title{
Modifikasi Perencanaan Struktur Gedung Tower C Apartemen Aspen Admiralty Jakarta Selatan Dengan Menggunakan Baja-Beton Komposit
}

\author{
Yhona Yuliana, Data Iranata, dan Endah Wahyuni \\ Departemen Teknik Sipil, Fakultas Teknik Sipil dan Perencanaan, Institut Teknologi Sepuluh \\ Nopember (ITS) \\ e-mail: iranata80@gmail.com, endah@ce.its.ac.id
}

\begin{abstract}
Abstrak-Gedung Tower C Apartemen Aspen Admiralty Jakarta Selatan terdiri dari 23 lantai dan 2 basement yang pada awalnya didesain dengan menggunakan struktur beton bertulang. Perencanaan sebelumnya didesain dengan ukuran kolom dan balok yang relatif besar, sehingga menambah berat sendiri dan akan membebani pondasi. Dengan alasan tersebut, perlu diupayakan perampingan konstruksi strukturnya yaitu dengan memodifikasi struktur bangunan tersebut dengan menggunakan struktur beton komposit. Untuk penyelesaiannya akan dilakukan perancangan dimensi struktur komposit dan kemudian dilakukan analisis struktur dengan menggunakan program SAP2000 v14 untuk mendapatkan dimensi struktur yang optimal. Tujuan dari Studi ini adalah menghasilkan perencanaan struktur gedung komposit baja-beton yang rasional dengan memenuhi persyaratan keamanan struktur berdasarkan SNI 2847:2013, SNI 1729:2015, SNI 1726:2012, dan PPIUG 1983. Dari analisis dan hasil perhitungan diperoleh hasil, yaitu tebal plat bondeks $10 \mathrm{~cm}$, dimensi balok induk WF 450x30x11x18, dimensi kolom lantai $1-5 \mathrm{~K} 588 \times 300 \times 12 \times 20$, dimensi kolom 6-15 K500x200x10x16, dimensi kolom lantai 8-23 K400x200x8x13. Perencanaan pondasi menggunakan tiang pancang beton pracetak diameter $60 \mathrm{~cm}$ dengan kedalaman $30 \mathrm{~m}$.
\end{abstract}

Kata Kunci-Baja-Beton, Komposit, Apartemen.

\section{PENDAHULUAN}

$\mathrm{K}$ OTA Jakarta merupakan kota dengan jumlah penduduk yang padat. Kebutuhan akan sarana dan prasarana pendukung di kota tersebut juga sangat besar, salah satunya adalah kebutuhan tempat tinggal. Sementara itu, ketersediaan lahan di kota tersebut semakin sedikit, hal ini menjadi alasan mengapa bangunan Apartemen di kota Jakarta dibangun bertingkat tinggi dan salah satu contohnya adalah gedung Tower C Apartemen Aspen Admiralty Jakarta Selatan.

Proyek pembangunan gedung Tower C Apartemen Aspen Admiralty berlokasi di Jakarta Selatan memiliki 23 lantai dan 2 basement. Perencanaan apartemen ini akan dimodifikasi dengan beberapa penyesuaian, sesuai dengan keinginan pihak terkait. Modifikasi yang akan dilakukan adalah mengganti struktur yang telah direncanakan sebelumnya yaitu beton bertulang dengan struktur komposit baja dan beton. Dan dalam pengerjaan studi ini akan dimodifikasi serupa dengan keadaan gedung tersebut yaitu memiliki 23 lantai dan 2 basement dengan menggunakan Baja-Beton Komposit.

\section{TINJAUAN PUSTAKA}

Aksi komposit terjadi apabila dua batang struktural pemikul beban seperti pada pelat beton dan balok baja sebagai penyangganya dihubungkan secara menyeluruh dan mengalami defleksi sebagai satu kesatuan. (Salmon \& Johnson, 1997)
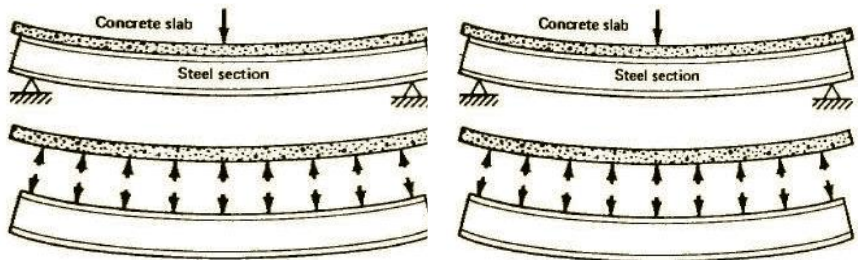

Gambar 1. Perbandingan antara balok yang melendut dengan dan tanpa aksi komposit. [1]

Pada balok komposit, pada bidang pertemuan antara pelat beton dan balok baja dipasang alat penghubung geser sehingga pelat beton dan balok baja bekerja sebagai satu kesatuan. Pada bidang kontak tersebut bekerja gaya geser vertikal dan horisontal, dimana gaya geser horisontal tersebut akan menahan perpanjangan serat bawah pelat dan perpendekan serat atas balok baja. Pada balok non komposit hanya bekerja gaya geser vertikal saja.

\section{HASIL DAN PEMBAHASAN}

\section{A. Preliminary Design}

Urutan dalam pengerjaan studi ini dilakukan dengan tahapan - tahapan sebagai berikut ini: 


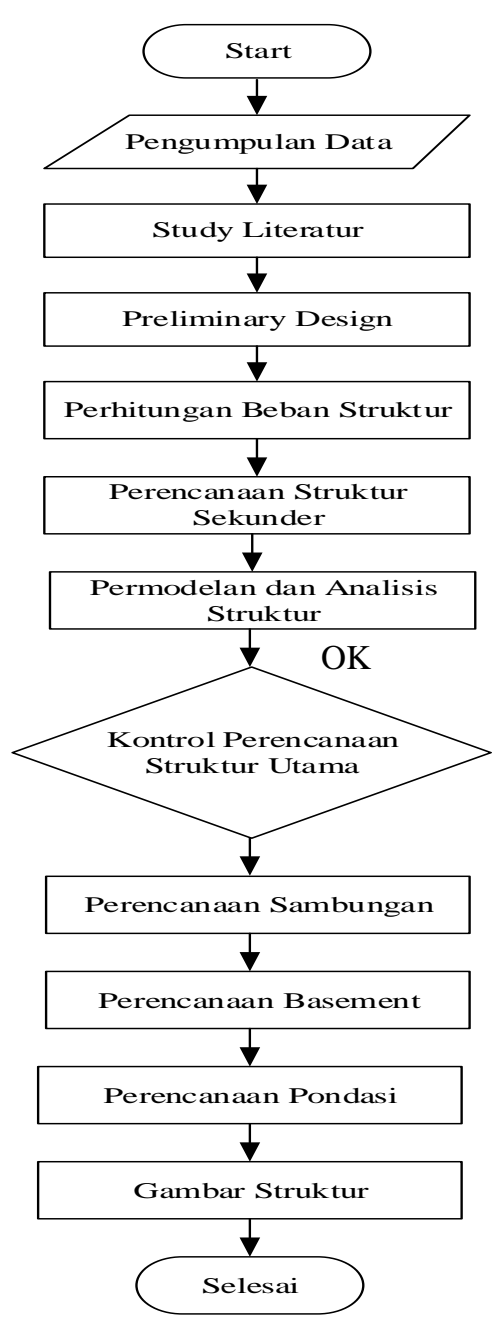

Gambar 2. Diagram Alir Penyelesaian Studi.

Data umum bangunan:

1. Nama gedung :Gedung Tower C Apartemen Aspen Admiralty Jakarta

2. Lokasi : Jakarta Selatan

3. Fungsi : Apartemen

4. Jumlah lantai : 23 lantai

5. Tinggi Gedung : $80,75 \mathrm{~m}$

6. Struktur utama : Komposit Baja-Beton

\section{B. Desain Struktur Sekunder}

1. Pelat lantai dan atap

Berdasarkan tabel perencanaan praktis untuk bentang menerus dengan tulangan negative, didapatkan data-data sebagai berikut:

Bentang $=3,2 \mathrm{~m}$

Beban berguna $=200 \mathrm{~kg} / \mathrm{cm}^{2}$

Tebal pelat beton $=10 \mathrm{~cm}$

Tulangan negatif $=2,70 \mathrm{~cm}^{2} / \mathrm{m}$

Dipasang tulangan negative Ø8-125

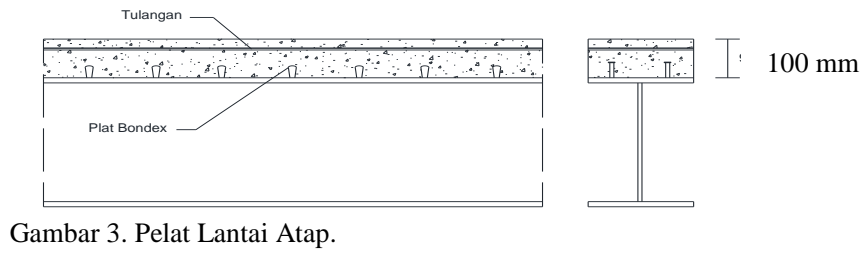

2. Tangga

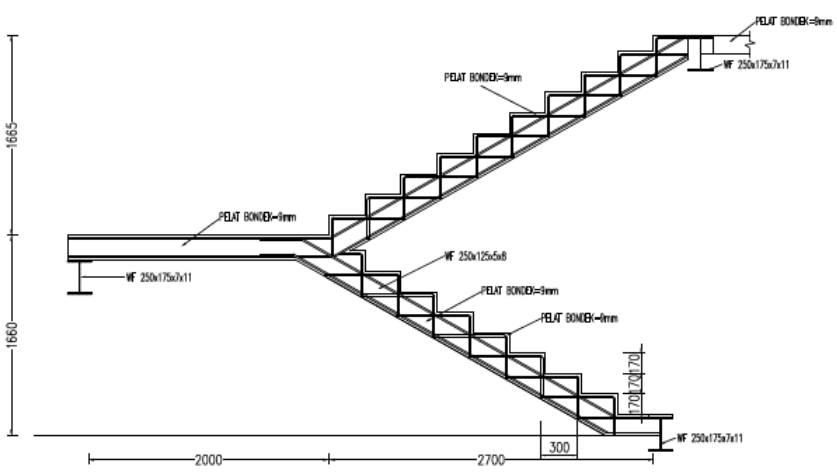

Gambar 4. Gambar Tangga.

Tinggi antar lantai $\quad: 332,5 \mathrm{~cm}$

Tinggi bordes $\quad: 200 \mathrm{~cm}$

Tinggi injakan (t) $: 17 \mathrm{~cm}$

Lebar injakan (i) $\quad: 30 \mathrm{~cm}$

Jumlah tanjakan $\left(\sum_{t}\right): 20$ buah

Jumlah injakan $\left(\sum_{i}\right)$ : 20-1=19 buah

Lebar bordes $\quad: 330 \mathrm{~cm}$

Panjang bordes $\quad: 200 \mathrm{~cm}$

Lebar tangga $\quad: 160 \mathrm{~cm}$

Sudut kemiringan $(\alpha): 31,6^{\circ}$

Direncanakan profil balok utama tangga dengan

WF $250 \times 125 \times 5 \times 8$

Direncanakan profil balok penumpu tangga dengan WF 250x175x7x11

Pengaku anak tangga $65 \times 65 \times 11$

Bordes dengan tebal $5 \mathrm{~mm}$

Balok bordes WF100x50x5x7

3. Perencanaan Balok Anak

Fungsi dari balok anak adalah serta membagi beban yang dipikul pelat lantai ke balok induk. Balok anak didesain sebagai sekunder sehingga dalam perhitungan tidak menerima beban lateral yang diakibatkan oleh gempa

Tabel 1.

Dimensi Balok Sekunder

\begin{tabular}{|c|c|}
\hline Elemen Balok & Jenis Profil \\
\hline Balok anak & WF300x300x9x14 \\
\hline Penumpu Lift & WF350x350x $13 \times 13$ \\
\hline Penggantung Lift & $350 \times 250 \times 8 \times 12$ \\
\hline
\end{tabular}

\section{Analisis Struktur utama}

Permodelan strktur gedung Tower C Apartemen Aspen Admiralty dilakukan dengan Program SAP 2000. Program ini 
akan membantu dalam beberapa perhitungan yang akan digunakan untuk mengecek apakah struktur sudah memenuhi persyaratan yang ada di SNI 1726:2012 [2] (Gempa) dan SNI 1729:2015 (Baja). [3]

Berikut adalah permodelan yang sudah dilakukan dari program SAP 2000.

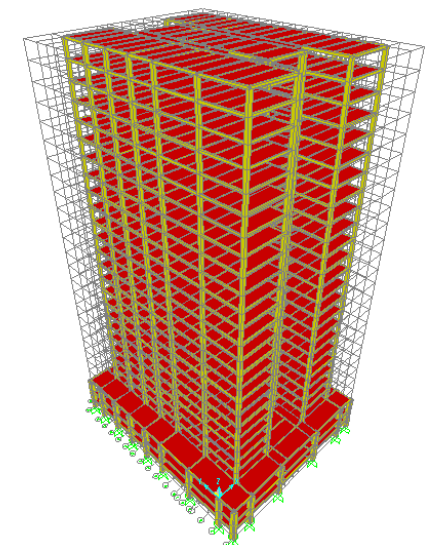

Gambar 5. Kontrol Perencanaan Struktur utama.

Analisis struktur Terhadap beban Gempa

1. Kontrol Partisipasi Massa

Partisipasi massa harus menyertakan ragam terkombinasi minimal 90\% dari massa aktual.

Tabel 2.

Kontrrol Nilai Partisipasi Massa

\begin{tabular}{ccccc}
\hline $\begin{array}{c}\text { OutputCase } \\
\text { Text }\end{array}$ & $\begin{array}{c}\text { StepType } \\
\text { Text }\end{array}$ & $\begin{array}{c}\text { StepNum } \\
\text { Unitless }\end{array}$ & $\begin{array}{c}\text { SumUX } \\
\text { Unitless }\end{array}$ & $\begin{array}{c}\text { SumUY } \\
\text { Unitless }\end{array}$ \\
\hline MODAL & Mode & 1 & 0,035 & $3,345 \mathrm{E}-07$ \\
MODAL & Mode & 2 & 0,685 & 0,000001117 \\
MODAL & Mode & 3 & 0,685 & 0,696 \\
MODAL & Mode & 4 & 0,689 & 0,696 \\
MODAL & Mode & 5 & 0,822 & 0,696 \\
MODAL & Mode & 6 & 0,822 & 0,82 \\
MODAL & Mode & 7 & 0,823 & 0,82 \\
MODAL & Mode & 8 & 0,877 & 0,82 \\
MODAL & Mode & 9 & 0,877 & 0,875 \\
MODAL & Mode & 10 & 0,877 & 0,875 \\
MODAL & Mode & 11 & 0,902 & 0,875 \\
MODAL & Mode & 12 & 0,909 & 0,875 \\
MODAL & Mode & 13 & 0,909 & 0,908 \\
MODAL & Mode & 14 & 0,91 & 0,908 \\
MODAL & Mode & 15 & 0,91 & 0,908 \\
\hline \hline
\end{tabular}

2. Kontrol Waktu Alami Fundamental

Perkiraan periode alami fundamental (Ta) dalam detik, harus ditentukan dengan persamaan berikut:

$\mathrm{C}_{\mathrm{t}}=0,0724$

$\mathrm{x}=0,8$

$\mathrm{h}_{\mathrm{n}}=80,75 \mathrm{~m}$

maka:
$\mathrm{T}=0,0724 \times 80,75^{0.8}$

$=2,43 \mathrm{~s}$

Nilai $\mathrm{C}_{\mathrm{u}}$ didapat dari tabel 14 SNI 1726:2012, untuk nilai $\mathrm{S}_{\mathrm{Dl}}=0,56$, maka :

$\mathrm{C}_{\mathrm{u}} \cdot \mathrm{T}=1,4 \times 2,44=3,4 \mathrm{~s}$

Tabel 3.

Kontrol Perioda Alami Fundamental

\begin{tabular}{ccc}
\hline $\begin{array}{c}\text { OutputCase } \\
\text { Text }\end{array}$ & $\begin{array}{c}\text { StepNum } \\
\text { Unitless }\end{array}$ & $\begin{array}{c}\text { Period } \\
\text { Sec }\end{array}$ \\
\hline MODAL & 1 & 2,445 \\
MODAL & 2 & 2,204 \\
MODAL & 3 & 2,062 \\
MODAL & 4 & 0,798 \\
MODAL & 5 & 0,674 \\
MODAL & 6 & 0,641 \\
MODAL & 7 & 0,446 \\
MODAL & 8 & 0,344 \\
MODAL & 9 & 0,334 \\
MODAL & 10 & 0,295 \\
MODAL & 11 & 0,217 \\
MODAL & 12 & 0,216 \\
MODAL & 13 & 0,210 \\
MODAL & 14 & 0,170 \\
MODAL & 15 & 0,161 \\
\hline
\end{tabular}

Dari tabel 3 didapat $\mathrm{T}=2.445 \mathrm{~s}$. Maka berdasarkan kontrol waktu getar alami fundamental nilai $\mathrm{T}$ masih lebih kecil dari $\mathrm{C}_{\mathrm{u}} \times \mathrm{T}$.

3. Kontrol Nilai Akhir Respon Spektrum

Tabel 4.

Kontrol Nilai Akhir Spektrum

\begin{tabular}{ccc}
\hline \hline Beban Gempa & Global FX (kg) & Global FY (kg) \\
\hline Gempa Arah X & 984470,45 & 316084,87 \\
Gempa Arah Y & 295369,66 & 984470,45 \\
\hline \hline
\end{tabular}

$\mathrm{V}_{\text {dinamik }} \geq 85 \% . \mathrm{V}_{\text {statik }}$

(3)

$984470,45 \mathrm{~kg} \geq 85 \% .1158201 \mathrm{~kg}$

$984470,45 \mathrm{~kg} \geq 984470,45 \mathrm{~kg}(\mathrm{OK})$

Untuk gempa arah Y:

$\mathrm{V}_{\text {dinamik }} \geq 85 \%$. $\mathrm{V}_{\text {statik }}$

$984470,45 \mathrm{~kg} \geq 85 \% .1158201 \mathrm{~kg}$

$984470,45 \mathrm{~kg} \geq 984470,45 \mathrm{~kg}(\mathrm{OK})$

4. Kontrol Simpangan Drift

Pembatasan simpangan antar lantai suatu struktur bertujuan untuk mencegah kerusakan non-struktur dan ketidaknyamanan penghuni. Berdasarkan SNI 1726:2012 Pasal 7.9.3[2] untuk memenuhi persyaratan simpangan digunakan rumus:

$\Delta_{\mathrm{i}} \leq \Delta_{\mathrm{a}}$

Dimana :

$\Delta_{\mathrm{i}}=$ Simpangan yang terjadi

$\Delta_{\mathrm{a}}=$ Simpangan ijin antar lantai 
Tabel 5.

Kontrol Simpangan Akibat Beban Gempa Ex

\begin{tabular}{|c|c|c|c|c|c|c|}
\hline \multirow{3}{*}{ Lantai } & \multirow{3}{*}{$\begin{array}{c}\text { Tinggi } \\
\text { Lantai } \\
\quad \mathbf{Z i} \\
\text { (m) }\end{array}$} & \multicolumn{5}{|c|}{ Gempa Arah X } \\
\hline & & \multicolumn{4}{|c|}{ Simpangan Arah X } & \multirow[t]{2}{*}{ Ket } \\
\hline & & $\Delta(\mathbf{m m})$ & $\begin{array}{c}\delta_{\mathrm{ei}} \\
(\mathbf{m m})\end{array}$ & $\begin{array}{c}\Delta_{\mathbf{i}} \\
(\mathbf{m m})\end{array}$ & $\begin{array}{c}\Delta_{\mathrm{a}} \\
(\mathbf{m m})\end{array}$ & \\
\hline 23 & 73,15 & 83,414 & 2,052 & 9,233 & 66,5 & $\mathrm{OK}$ \\
\hline 22 & 69,825 & 81,363 & 2,296 & 10,333 & 66,5 & OK \\
\hline 21 & 66,5 & 79,066 & 2,494 & 11,222 & 66,5 & OK \\
\hline 20 & 63,175 & 76,573 & 2,697 & 12,138 & 66,5 & OK \\
\hline 19 & 59,85 & 73,876 & 2,910 & 13,094 & 66,5 & OK \\
\hline 18 & 56,525 & 70,966 & 3,120 & 14,041 & 66,5 & OK \\
\hline 17 & 53,2 & 67,846 & 3,357 & 15,106 & 66,5 & OK \\
\hline 16 & 49,875 & 64,489 & 3,480 & 15,659 & 66,5 & OK \\
\hline 15 & 46,55 & 61,009 & 3,668 & 16,505 & 66,5 & $\mathrm{OK}$ \\
\hline 14 & 43,225 & 57,341 & 3,836 & 17,261 & 66,5 & OK \\
\hline 13 & 39,9 & 53,505 & 3,989 & 17,949 & 66,5 & OK \\
\hline 12 & 36,575 & 49,517 & 4,125 & 18,563 & 66,5 & OK \\
\hline 11 & 33,25 & 45,392 & 4,242 & 19,087 & 66,5 & OK \\
\hline 10 & 29,925 & 41,150 & 4,334 & 19,502 & 66,5 & OK \\
\hline 9 & 26,6 & 36,816 & 4,396 & 19,781 & 66,5 & OK \\
\hline 8 & 23,275 & 32,420 & 4,422 & 19,899 & 66,5 & OK \\
\hline 7 & 19,95 & 27,999 & 4,425 & 19,910 & 66,5 & OK \\
\hline 6 & 16,625 & 23,574 & 4,277 & 19,245 & 66,5 & OK \\
\hline 5 & 13,3 & 19,297 & 4,183 & 18,822 & 66,5 & OK \\
\hline 4 & 9,975 & 15,115 & 3,993 & 17,971 & 66,5 & OK \\
\hline 3 & 6,65 & 11,121 & 3,693 & 16,617 & 66,5 & OK \\
\hline 2 & 3,325 & 7,429 & 3,159 & 14,214 & 66,5 & OK \\
\hline 1 & 0 & 4,270 & 2,944 & 13,248 & 66,5 & OK \\
\hline-1 & $-4,6$ & 1,326 & 1,072 & 4,823 & 92 & OK \\
\hline-2 & -3 & 0,254 & 0,254 & 1,144 & 60 & OK \\
\hline
\end{tabular}

Tabel 6.

Kontrol Simpangan Akibat Beban Gempa Ey

\begin{tabular}{|c|c|c|c|c|c|c|}
\hline \multirow{3}{*}{ Lantai } & \multirow{3}{*}{$\begin{array}{c}\text { Tinggi } \\
\text { Lantai } \\
\quad \mathbf{Z i} \\
\text { (m) }\end{array}$} & \multicolumn{5}{|c|}{ Gempa Arah Y } \\
\hline & & \multicolumn{4}{|c|}{ Simpangan Arah Y } & Ket \\
\hline & & $\Delta(\mathbf{m m})$ & $\begin{array}{c}\delta_{\mathrm{ei}} \\
(\mathbf{m m})\end{array}$ & $\underset{(\mathbf{m m})}{\Delta_{\mathbf{i}}}$ & $\begin{array}{c}\Delta_{\mathbf{a}} \\
(\mathbf{m m})\end{array}$ & \\
\hline 23 & 73,15 & 21,166 & 0,558 & 2,511 & 66,5 & $\mathrm{OK}$ \\
\hline 22 & 69,825 & 20,608 & 0,612 & 2,753 & 66,5 & $\mathrm{OK}$ \\
\hline 21 & 66,5 & 19,996 & 0,654 & 2,944 & 66,5 & $\mathrm{OK}$ \\
\hline 20 & 63,175 & 19,342 & 0,703 & 3,162 & 66,5 & $\mathrm{OK}$ \\
\hline 19 & 59,85 & 18,639 & 0,753 & 3,388 & 66,5 & $\mathrm{OK}$ \\
\hline 18 & 56,525 & 17,887 & 0,801 & 3,605 & 66,5 & OK \\
\hline 17 & 53,2 & 17,085 & 0,854 & 3,843 & 66,5 & $\mathrm{OK}$ \\
\hline 16 & 49,875 & 16,231 & 0,886 & 3,989 & 66,5 & $\mathrm{OK}$ \\
\hline 15 & 46,55 & 15,345 & 0,930 & 4,183 & 66,5 & $\mathrm{OK}$ \\
\hline 14 & 43,225 & 14,415 & 0,967 & 4,352 & 66,5 & OK \\
\hline
\end{tabular}

\begin{tabular}{ccccccc}
\hline \hline 13 & 39,9 & 13,448 & 1,001 & 4,506 & 66,5 & OK \\
12 & 36,575 & 12,447 & 1,032 & 4,642 & 66,5 & OK \\
11 & 33,25 & 11,415 & 1,057 & 4,757 & 66,5 & OK \\
10 & 29,925 & 10,358 & 1,077 & 4,848 & 66,5 & OK \\
9 & 26,6 & 9,281 & 1,091 & 4,908 & 66,5 & OK \\
8 & 23,275 & 8.190 & 1,096 & 4,933 & 66,5 & OK \\
7 & 19,95 & 7,094 & 1,096 & 4,931 & 66,5 & OK \\
6 & 16,625 & 5,998 & 1,068 & 4,805 & 66,5 & OK \\
5 & 13,3 & 4,930 & 1,044 & 4,699 & 66,5 & OK \\
4 & 9,975 & 3,886 & 0,998 & 4,489 & 66,5 & OK \\
3 & 6,65 & 2,889 & 0,926 & 4,166 & 66,5 & OK \\
2 & 3,325 & 1,963 & 0,806 & 3,628 & 66,5 & OK \\
1 & 0 & 1,157 & 0,797 & 3,585 & 66,5 & OK \\
-1 & $-4,6$ & 0,360 & 0,292 & 1,312 & 92 & OK \\
-2 & -3 & 0,068 & 0,068 & 0,307 & 60 & OK \\
\hline \hline
\end{tabular}

5. Kontrol Sistem Ganda

Dalam studi ini digunakan Sistem Rangka Pemikul Momen Khusus dengan Dinding Geser Beton Bertulang Khusus.

Menurut SNI 1726:2012 pasal 7.2.5.1[2], bahwa untuk system ganda, rangka pemikul momen harus mampu menahan paling sedikit $25 \%$ gaya gempa desain. Tahanan gaya gempa total harus disediakan oleh kombinasi rangka pemikul momen dan dinding geser atau bresing, dengan distribusi yang proposional terhadap kekauannya.

Tabel 7.

Kontrol Sistem Ganda

\begin{tabular}{|c|c|c|c|c|c|}
\hline TOTAL & $\begin{array}{c}446745,3 \\
5 \\
\end{array}$ & 234892,9 & $\begin{array}{c}208253 \\
, 57 \\
\end{array}$ & $\begin{array}{c}453413, \\
25 \\
\end{array}$ & Ket \\
\hline$\%$ SRPMK & 35,75 & 33,31 & 35,25 & 33,17 & Ok \\
\hline $\begin{array}{l}\text { \% DINDING } \\
\text { GESER }\end{array}$ & 65,26 & 66,69 & 64,75 & 67,83 & Ok \\
\hline
\end{tabular}

F. Sambungan

Sambungan antara balok induk dan balok anak menggunakan sambungan siple conection. Dengan rumus

Kuat geser

$\varnothing \mathrm{Vn}=\varnothing \times \mathrm{r}_{1} \times \mathrm{fu}^{\mathrm{b}} \times \mathrm{Ab} \times \mathrm{fu}$

Kuat tumpu:

$\varnothing \mathrm{Rn}=\varnothing \times 2,4 \times \mathrm{db} \times \mathrm{tp} \times \mathrm{fu}$

Sambungan antara balok induk dengan kolom menggunakan sambungan rigid conection

> Sambungan kolom dengan kolom digunakan baut diamater (Ø28)

> Pada sambungan baseplate dengan kolom didapatkan tebal baseplate $4 \mathrm{~cm}$ dengan angkur praktis $(8 \varnothing 25)$

1. Sambungan balok anak dengan balok induk 


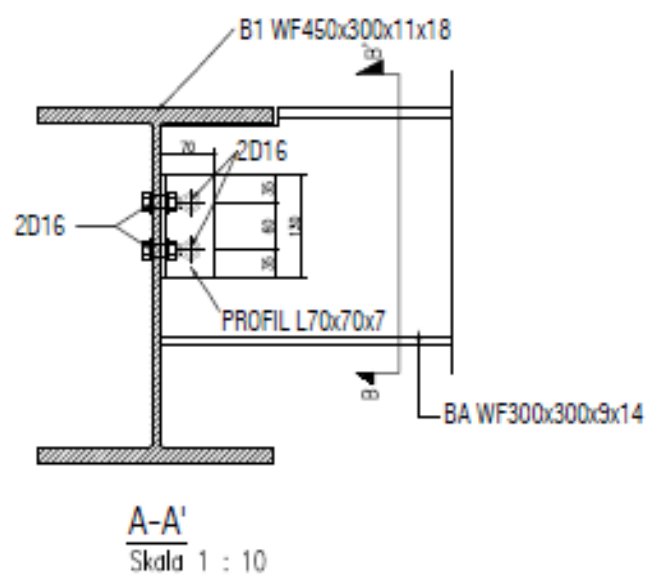

Gambar 6. Sambungan balok anak dengan balok induk.

2. Sambungan antar kolom

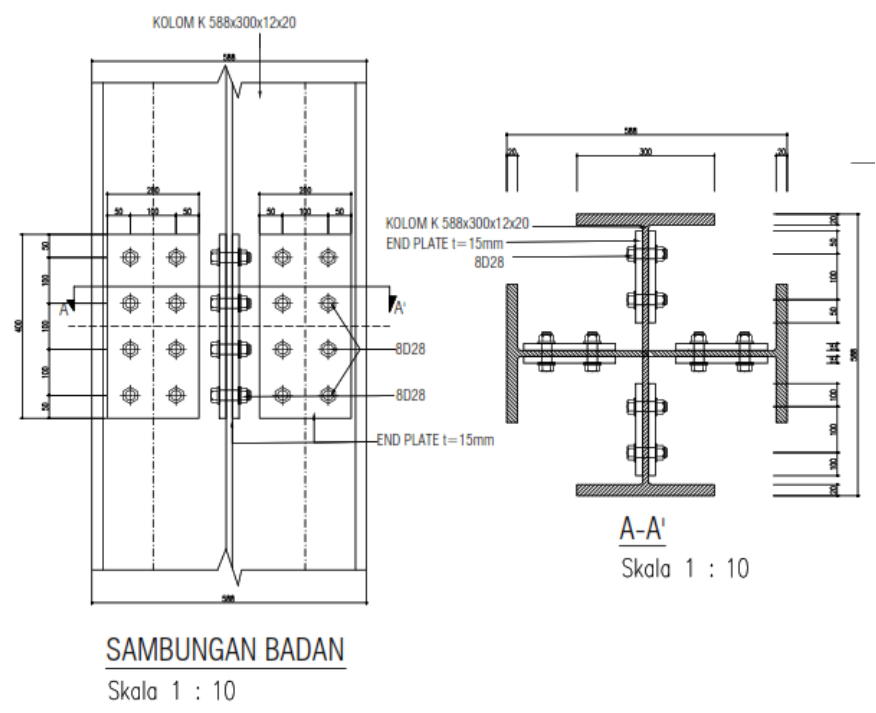

Gambar 7. Sambungan antar kolom.

3. Sambungan Kolom dengan Base Plate

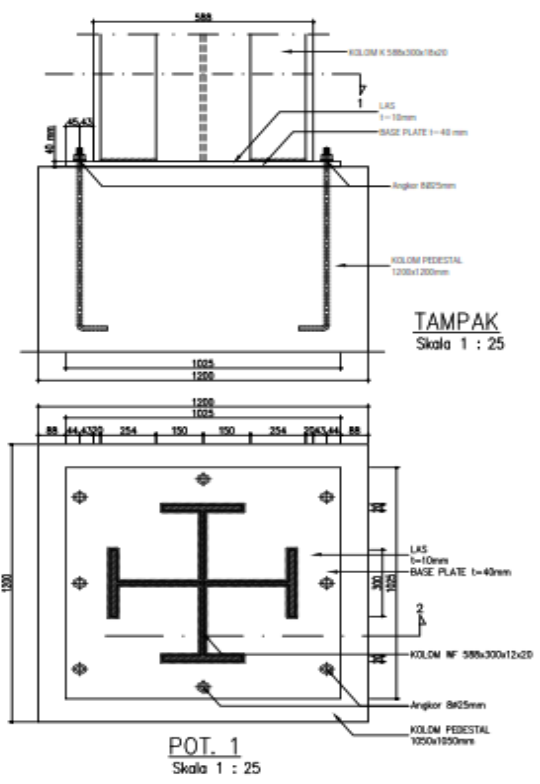

Gambar 8. Sambungan balok induk dengan kolom.

\section{G. Pondasi}

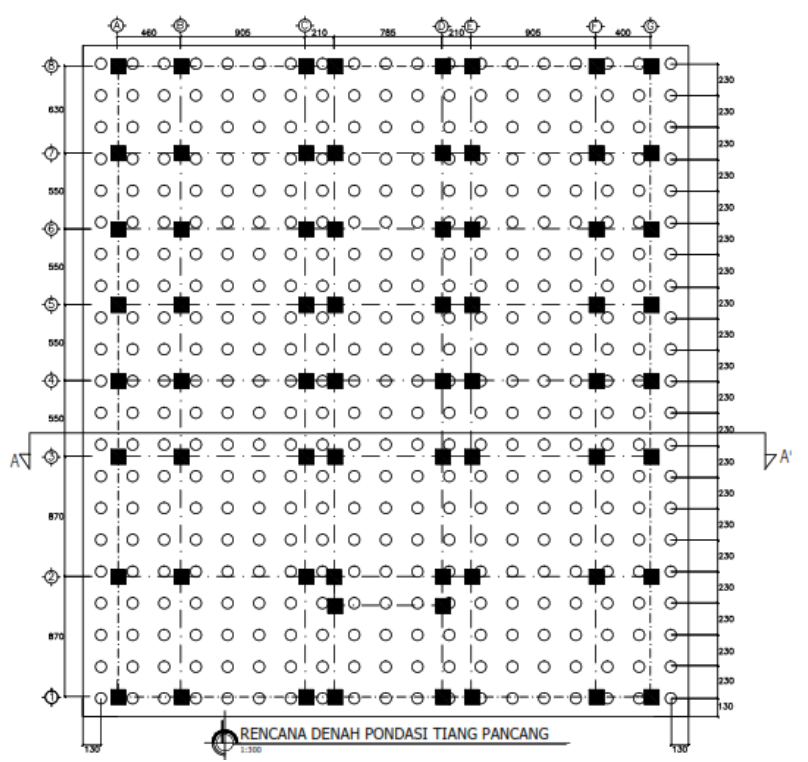

Gambar 9. Denah tiang pancang.

Dalam perencanaan pondasi direncanakan dengan diameter $60 \mathrm{~cm}$ dengan kedalaman $30 \mathrm{~m}$. Dengan daya dukung ijin tiang pancang $\left(\mathrm{P}_{\mathrm{ijin}}=120,42\right.$ ton). Pondasi menggunakan data SPT terlampir.

\section{KESIMPULAN}

Dari hasil analisis dan perhitungan pada studi ini, maka dapat diambil beberapa kesimpulan sebagai berikut:

1. Dilakukan perhitungan struktur sekunder terlebih dahulu seperti perhitungan tangga, pelat lantai, dan balok anak terhadap beban-beban yang bekerja baik beban mati, beban hidup maupun beban terpusat.

2. Dilakukan kontrol terhadap balok utama pada kondisi sebelum komposit dan kondisi setelah komposit. Kontrol yang dilakukan meliputi : kontrol lendutan, kontrol penampang (local buckling), kontrol lateral buckling dan kontrol geser.

3. Dilakukan kontrol kekuatan struktur kolom komposit yang meliputi kontrol luas minimum beton pada kolom komposit, perhitungan kuat tekan aksial kolom, perhitungan kuat lentur kolom, dan kontrol kombinasi aksial dan lentur.

4. Rigid connection digunakan untuk sambungan antara balok-kolom. Simple connection digunakan pada sambungan balok anak dengan balok induk.

5. Dimensi - dimensi dari struktu yang digunakan adalah sebagai berikut :

- Dimensi kolom komposit:

Profil : K 588 x 300 x 18 x 20 (Beton 850x850)

K 500x200x10x16 (Beton $=700 \times 700)$

$\mathrm{K} 400 \times 200 \times 8 \times 13($ Beton $=600 \times 600)$

- Profil balok induk komposit:

WF $450 \times 350 \times 11 \times 18$

- Profil balok anak komposit:

WF $300 \times 300 \times 9 \times 14$ 
- Profil balok lift :

Penggantung : WF $350 \times 250 \times 8 \times 12$

Penumpu : WF $350 \times 250 \times 9 \times 14$

- Profil balok tangga :

Utama : WF 250 x $125 \times 5 \times 8$

Penumpu : WF $250 \times 175 \times 7 \times 11$

- Tiang pancang diameter $60 \mathrm{~cm}$ dengan kedalaman $30 \mathrm{~m}$

\section{DAFTAR PUSTAKA}

[1] C. \& J. E. J. G. Salmon, Struktur Baja Desain Dan Prilaku. Jakarta: Erlangga, 1991.

[2] Badan Standarisasi Nasional, SNI 1729-2012 Tata Cara Ketahanan Gempa Untuk Struktur Bangunan Gedung dan Non Gedung. .

[3] Badan Standarisasi Nasional, SNI 1729:2015 Tata Cara Perhitungan Struktur Baja Untuk Bangunan Gedung. 